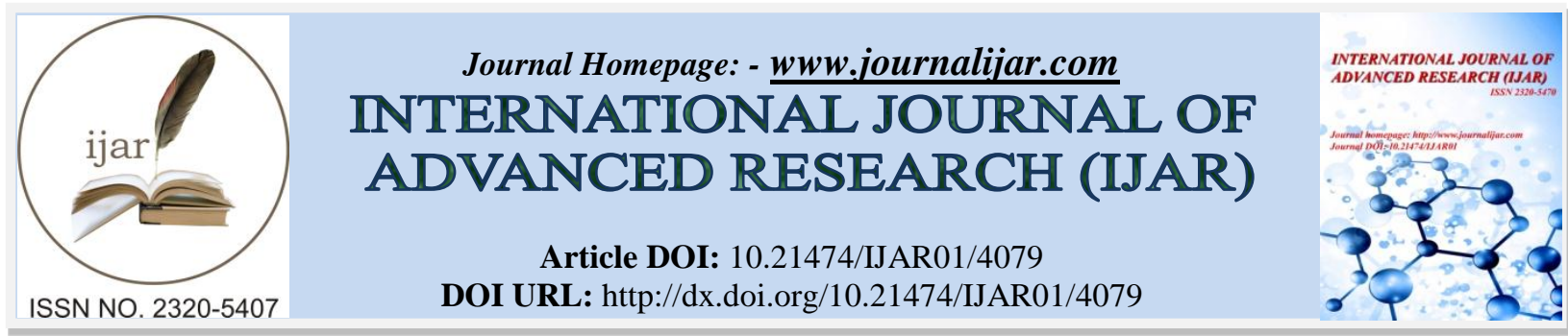

RESEARCH ARTICLE

\title{
INCIDENCE OF NUTRITIONAL HEALTH ASSOCIATED DISEASES AMONGST CHILDREN IN THE HEALTH DISTRICT OF ABONG MBANG, CAMEROON.
}

\section{Samuel Nambile. Cumber ${ }^{2,3},{ }^{*}$ Jackson Jr N. Ndenkeh ${ }^{1,2,4}$, Joyce Mahlako Tsoka-Gwegweni ${ }^{3}$ and Joseph Noupoue 4 .}

1. Department of Biomedical Sciences, University of Dschang, Cameroon.

2. Under Privileged Children and Women Assistance (UPCAWA), Cameroon.

3. Discipline of Public Health Medicine, Department of Nursing \& Public Health, College of Health Sciences, University of KwaZulu-Natal, Durban, South Africa.

4. District Health Service of Abong Mbang, Cameroon.

\section{Manuscript Info}

(.........................

Manuscript History

Received: 01 March 2017

Final Accepted: 09 April 2017

Published: May 2017

Key words:-

.Incidence; Malnutrition; Diarrhoea;

Malaria; Anemia; Children; Abong

Mbang; Cameroon

\section{Abstract}

Introduction: Despite the prevalence of malnutrition in developing countries, it is rarely given the attention it deserves as one of the leading cause of infant morbido-mortality. Rather diseases like diarrheal diseases, malaria and other communicable diseases are given more attention while forgetting the underlying role of malnutrition in the deterioration of the health status of these children. The objective of this study was thus to determine the incidence of nutritional health associated health problems which include diarrhoea, malaria and anemia with respect to space and time as well as their correlations to malnutrition in the context of Abong Mbang.

Methods: This study was carried out in the Health District of Abong Mbang determining the incidence of nutritional health associated diseases amongst children using data from monthly activity reports collected from January 2015 through June 2016. The correlations between each disease and malnutrition were also calculated setting significance set at $5 \%$.

Results: The results showed a significant increase in the reported incidence of the above health problems between 2015 and 2016. We also noted higher incidences in Abong Mbang Centre, Abong Mbang Sud and Mbomba Health Areas. Malnutrition had a moderate degree of correlation with diarrhoea though there was no compelling evidence of that correlation being real and not due to chance; with R-square and pvalue of 0.415 and 0.167 respectively.

Conclusion: There was a significant increase in the reported incidence of the above health problems amongst children in Abong Mbang. Although there was no compelling evidence of real correlation between malnutrition and diarrhoea, there is need for further research to determine etiological relationships between the two in the context of the Health District of Abong Mbang.

Copy Right, IJAR, 2017,. All rights reserved. 


\section{Introduction:-}

Malnutrition continues to be a major health problem in developing countries and is a substantial contributor to childhood morbidity and mortality (1). Worldwide there are about 60 million children with moderate acute and 13 million with severe acute malnutrition (2). Undernutrition is associated with at least $35 \%$ of child deaths and is a risk factor for poor cognitive development, reduced human capital, premature death and other health consequences(2). Despite its high prevalence in these resource limited countries, it is still rarely considered as such. Attention is most at times drifted more towards direct causes like diarrhoea, acute respiratory illness, malaria and other communicable diseases or related health problem (3). Malnutrition is the associated cause for about half of the deaths that occur among under-five children in developing countries (4). Children are highly vulnerable to malnutrition especially at their early years. They constitute about $12.5-15 \%$ of world populations while having a mortality rate of $25-30 \%$ in developing countries (5).

Malnutrition has a close relationship with other health problems in children like diarrhoea, anemia and malaria (1, 6). The relationship between diarrhoea and malnutrition is bidirectional; diarrhoea leads to malnutrition while malnutrition aggravates the course of diarrhoea(3, 6, 7). In developing countries, children under the age of three years suffer from average three episodes of diarrhoea per year. Each episode worsens the nutritional status of the body necessary for growth and development of the children. Consequently, it is a major cause of malnutrition, and malnourished children are highly susceptible to further attacks of diarrhoea(7). According to a recent WHO report on the global prevalence of anemia, one in four people is affected by anemia worldwide (8). Malnutrition can lead to anemia especially when child's diet is not equilibrated leading to micronutrient insufficiency $(1,5)$. Iron deficiency anemia (IDA) is the most prevalent nutritional disorder in the world despite iron being the fourth most common element on earth (9). The synergistic relation between malnutrition and infection is well known, and nutritional interventions have been recognized as an important approach for reducing mortality from acute respiratory illness and diarrhea (10). A malnourished child is more vulnerable to infection as compared to a nutritionally healthy child thus that child is opened to increased morbidity to common communicable diseases like malaria $(4,11)$.

The primary objective of this study was thus to determine the incidence of nutritional health associated diseases (or related health problem) which include diarrhoea, malaria and anemia with respect to space and time while the secondary objective was to determine their correlations to malnutrition in the context of Abong Mbang. Here we determined if the trends were similar to that of the incidence of malnutrition in the Health District with respect to temporal change and their geographical distribution in the various Health Areas in Abong Mbang. Furthermore, the determination of their correlations to the latter (and significance) would help provide evidence if their trends were somehow linked to that of malnutrition. The results from this study will provide basis for further research as well as intervention at community level as concerns malnutrition and its underlying factors.

\section{Methodology:-}

This was cross sectional study done through a documentary investigation in the Health District of Abong Mbang which is found in the East region of Cameroon. This study carried out using data from available monthly activity reports from the various health areas which dated from January 2015 to June 2016. The data collected from the above monthly reports was done using an exhaustive sampling method from all available reports forwarded to the District Service since January 2015 and from all available health facilities of the Health District. This study focused on health problems of children less than 5 years which included malnutrition, diarrhea, malaria, anemia etc. The above data which is non-identifiable and public available data was collected upon the award of a written authorization by the District Medical Officer of the Health District. After entering the data in an excel spreadsheet, frequencies were calculated where appropriate as well as comparison done using the Chi ${ }^{2}$ test with significance set at 5\%. Also the correlations between each health problem and malnutrition were determined using the Spearman's correlation with 2-tailed significance set at 5\%. Here the number of reported cases of each health problem was distributed per health area and per time period as well as comparisons done for the latter. The main predictor tested for correlation with malnutrition here was diarrhea while anemia and malaria were potential confounders.

\section{Results:-}

The Health District of Abong Mbang is made up of a total population of 73,703 and children population of 14004 sub-divided into 12 health areas as shown in table 1 below. Amongst these health areas the peri-urban ones are the Abong Mbang North, South and Center while the rural and furthest ones from the town of Abong Mbang include Djaposten, Mindourou and Akok Maka. The most populated of these health areas include Angossas, Mbomba and 
Abong Mbang South with populations of 10694, 9825 and 8833 respectively. Each health area has atleast one Integrated/Community Health Center in addition to two Sub-Divisional Medical Centers found in Angossas and Atok as well as a District Hospital found in Abong Mbang South, summing up to a total of 22 functional health facilities.

Table 1:- Demographic information of the Health District

\begin{tabular}{|l|l|l|l|l|l|}
\hline No & Health area & General population & \multicolumn{2}{l|}{ Population of children } \\
\hline & Year & $\mathbf{2 0 1 5}$ & $\mathbf{2 0 1 6}$ & $\mathbf{2 0 1 5}$ & $\mathbf{2 0 1 6}$ \\
\hline 1 & Abong Mbang Centre & 6761 & 6957 & 1285 & 1322 \\
\hline 2 & Abong Mbang North & 6275 & 6455 & 1192 & 1226 \\
\hline 3 & Abong Mbang South & 8585 & 8833 & 1631 & 1678 \\
\hline 4 & Akok Maka & 5525 & 5685 & 1050 & 1080 \\
\hline 5 & Angossas & 10394 & 10694 & 1975 & 2032 \\
\hline 6 & Ankoung & 3005 & 3092 & 571 & 587 \\
\hline 7 & Atok & 6586 & 6776 & 1251 & 1287 \\
\hline 8 & Djaposten & 2621 & 2696 & 498 & 512 \\
\hline 9 & Kwoamb & 610 & 627 & 116 & 119 \\
\hline 10 & Mbomba & 9549 & 9825 & 1814 & 1867 \\
\hline 11 & Mindourou & 5765 & 5932 & 1095 & 1127 \\
\hline 12 & Nkouak & 5959 & 6131 & 1132 & 1165 \\
\hline & TOTAL & $\mathbf{7 1 6 3 5}$ & $\mathbf{7 3 7 0 3}$ & $\mathbf{1 3 6 1 1}$ & $\mathbf{1 4 0 0 4}$ \\
\hline
\end{tabular}

A study conducted by Cumber et al gives a detailed geographical distribution and comparison of the incidences of malnutrition in the first semesters of both 2015 and 2016 in the Health District of Abong Mbang (12). In the above study malnutrition was found to be more around the town of Abong Mbang as well as a statistically significant difference was noted in its incidence between the first semester of 2015 and 2016 with Chi-square and p-value 12.83 and 0.0003 respectively (12).

Figure 1 below shows the geographical distribution of diarrhoea, malaria and anemia in the various Health Areas of the Health District. We note that malaria was most incident in Abong Mbang Centre, Abong Mbang Sud, Mbomba and Nkouak which is the same trend noted for diarrhoea incidence (while including Angossas for the latter). Anemia on the hand was most incident only in Abong Mbang Centre and Abong Mbang Sud while the other Health Areas had some spontaneous number of cases reported.

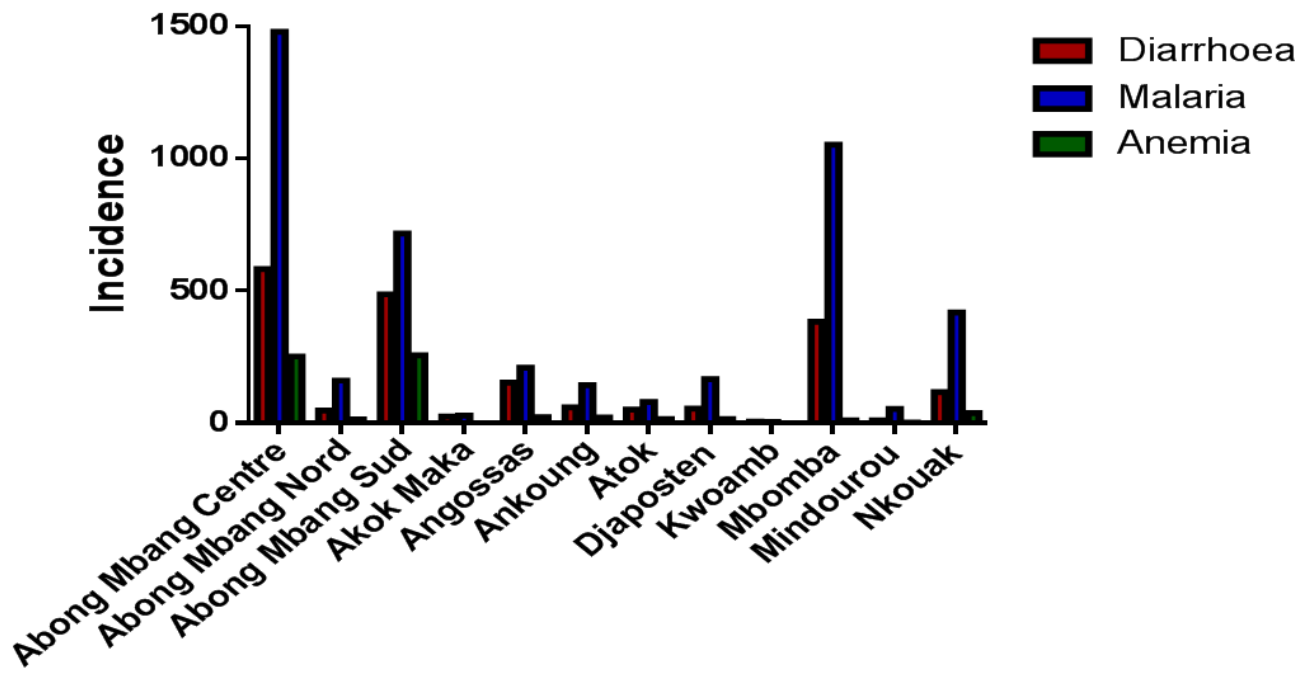

Health Areas

Figure 1:- Distribution per Health Area

Within the whole year of 2015, the Health District of Abong Mbang reported a total of 689, 1,939 and 197 cases of diarrhoea, malaria and anemia respectively while within the first 6 months of 2016 for the same health problems 
above we noted 645, 1,311 and 227 cases respectively. When comparisons were done between the first semesters of 2015 and 2016 using the Chi-square at 5\% significance, it was noted that all three health problems amongst children were significantly higher in 2016 than 2015 as shown on table 2 below (p-values $<0,0001$ ).

Table 2:- Comparison of incidence between 2015 and 2016

\begin{tabular}{|l|l|l|l|l|}
\hline & Jan-June 2015 & Jan-June 2016 & Chi-square; df & P-value \\
\hline Diarrhoea & 340 & 645 & 88,$55 ; 1$ & $<0,0001$ \\
\hline Malaria & 730 & 1325 & 163,$4 ; 1$ & $<0,0001$ \\
\hline Anemia & 67 & 227 & 82,$42 ; 1$ & $<0,0001$ \\
\hline
\end{tabular}

Figure 2 below shows the quarterly distribution of malnutrition and its associated health problems from January 2015 all through the first two quarterly periods of 2016. In 2015 we noted a general increase in the reported incidence of malaria, malnutrition and anemia especially during the second and/or third trimesters. During this same year, the increase was very mild for diarrhoea with the highest incidence noted in the third trimester. In 2016 we noted that the incidence of malaria had dropped at the start of the year but started increasing within the subsequent months. On the other hand malnutrition, diarrhoea and anemia started the year with higher figures as compared to those of the formal year with an increasing trend for anemia and decreasing trends for malnutrition and diarrhoea.

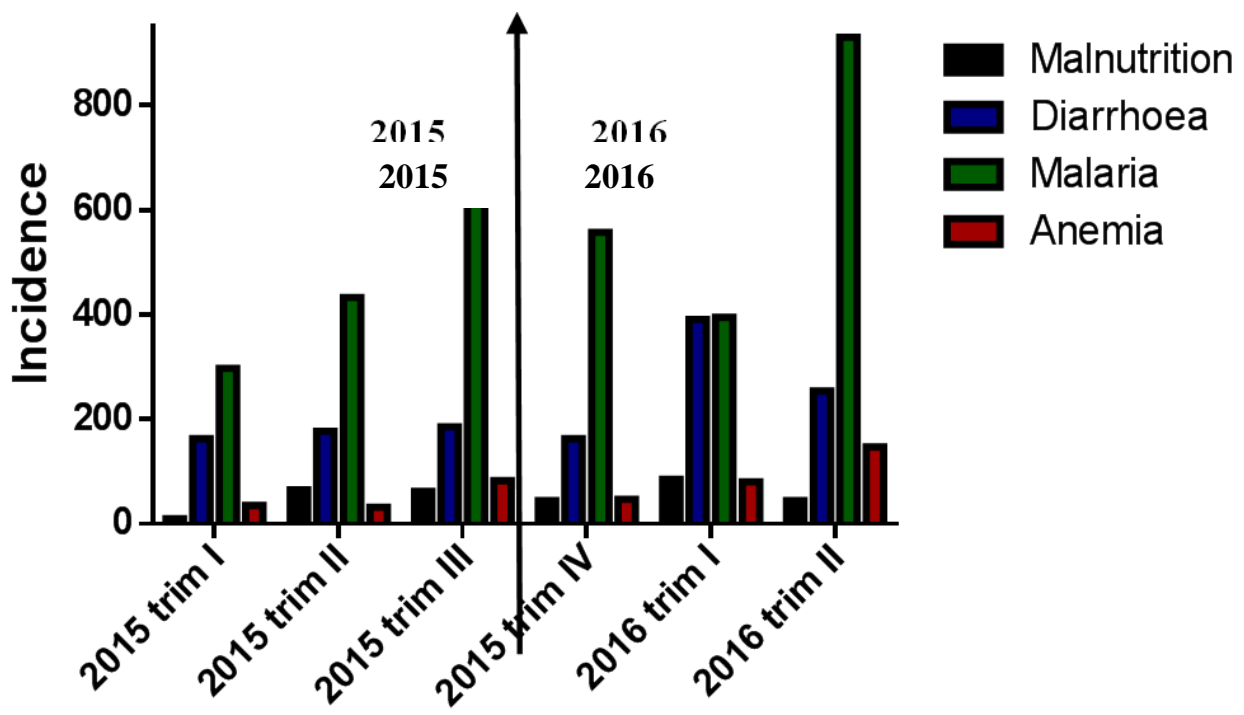

\section{Quarterly periods}

Figure 2:- Distribution per quarterly periods

When the above quarterly figures were computed for correlation; using the Spearman' correlation (r), we noted in this data that there was a positive correlation between all the three health problems though these correlations were very weak for malaria and anemia. On the other hand malnutrition had a moderate degree of correlation with diarrhoea (with R-square of 0.415). The significance of this correlation between malnutrition and diarrhoea (as noted from the p-value of 0.167 ) however did not give any reason to conclude that the correlation was real and not by chance (table 3 and figure 3 ).

Table 3:- Correlation with malnutrition

\begin{tabular}{|l|l|l|l|}
\hline Malnutrition & Diarrhoea & Malaria & Anemia \\
\hline $\mathrm{R}$ value & 0.644 & 0.073 & 0.192 \\
\hline $\mathrm{R}$ square & 0.415 & 0.005 & 0.037 \\
\hline P-value & 0.167 & 0.890 & 0.715 \\
\hline
\end{tabular}




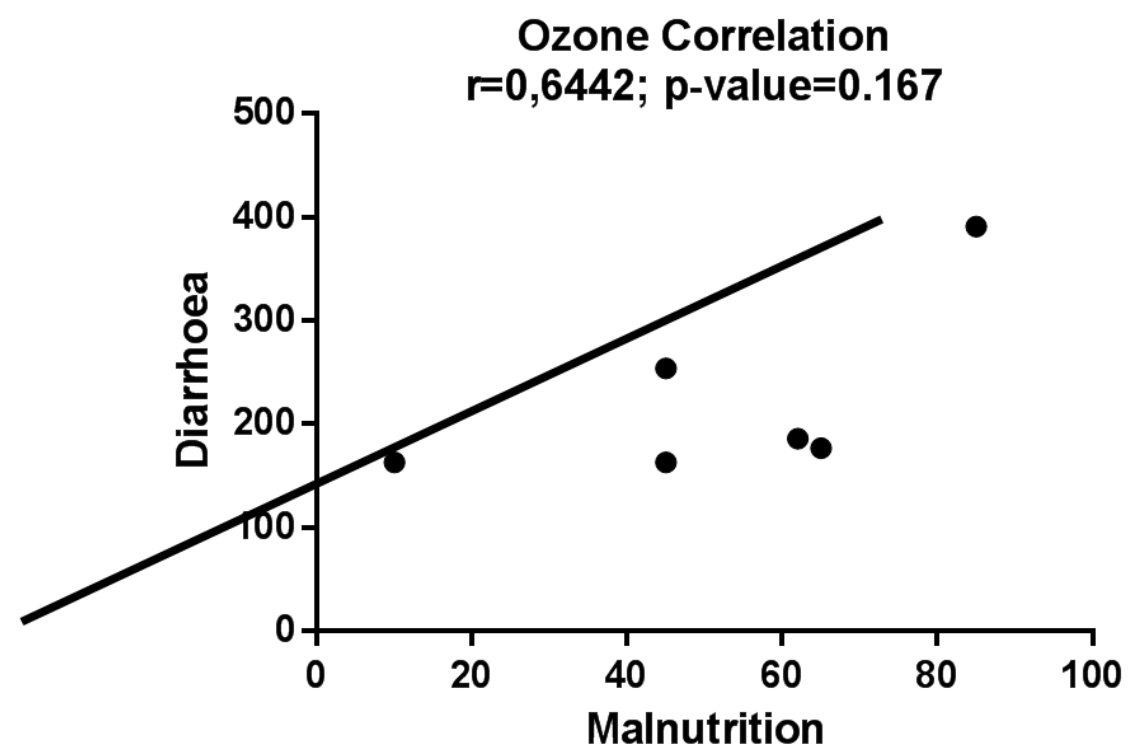

\section{Discussion:-}

Figure 3:- Correlation between malnutrition and diarrhoea

Many studies implemented worldwide have shown the bi directional association between malnutrition and diarrhea as well as the influence of the former on morbido-mortality vis-à-vis other infectious diseases like malaria and HIV presently rocking Africa $(1,3,6,7)$. This study was thus carried with the objective of determining the incidence of nutritional health associated health problems in children with respect to time and space while also determining the correlations between the malnutrition and the formers. We proceeded by implementing a documentary investigation using data on health problems in children from the monthly activity reports between January 2015 through June 2016.

The results of this study showed that diarrhoea, malaria and anemia were most preponderant in the health areas of Abong Mbang Centre and Abong Mbang Sud. Also some other health areas high reported incidences like Mbomba and Nkouak in the case of malaria and diarrhoea as well as Angossas in the case of diarrhoea. The difference in the geographical distribution can be due to difference in infrastructures in the various health facilities between the health areas. Urban health areas have better health facilities (public and/or private) with better infrastructure and quality of personnel thus more likely to have more visits/cases. Also on the other hand under reporting can lead to lower reported incidences in the other health areas so this geographical distribution cannot be confirmed with certainty. However the similarity in the geographical distribution of the above health problems with the trends determined by Cumber et al in the same context as concerned malnutrition is worth noting (12). Cumber et al noted the highest reported incidence of malnutrition Abong Mbang Nord, Abong Mbang Sud, Abong Mbang Centre and Mbomba health areas (12).

We also noted a general increase in the reported incidences of diarrhoea, malaria and anemia. All these health problems had statistically significant differences when first semesters of both years were compared. These differences go in accordance with that noted by Cumber et al in the same context as concerned malnutrition. The above findings gave grounds for the thought of a possible association between the above health problems and malnutrition in the context of the Health District Abong Mbang(12). However when tested for correlation, a moderate correlation was noted only between malnutrition and diarrhoea though there was no compelling evidence showing that the correlation between malnutrition and diarrhoea was real and not due to chance ( $p$-value $=0.167)$.

There is a general problem of accessibility to potable water as well as poor sanitation in the Health District of Abong Mbang especially in the distant/rural health areas, as it is the general situation in the East region of Cameroon (13). It can be one of the main etiological factors of diarrhoea and this latter can lead to poor absorption in the gut, lack of appetite vomiting etc which can lead to malnutrition in general and micronutrient insufficiencies in particular; for instance iron deficiency leading to anemia in children(6). Furthermore, Malnutrition is a predisposing factor to vulnerability to common infections which in this context is malaria $(4,14)$. The cross sectional aspect of this study and the fact that it was a documentary investigation did not permit the advent of these relationships though a 
moderate correlation was noted between malnutrition and diarrhoea. There is thus the need to go further in research in the above research domain with a more appropriate research methodology (a longitudinal study) to appreciate the effect malnutrition has on each of these health problems and/or vice versa.

This study was carried out on the available data in the District Health Service of Abong Mbang and it was however noted that not all health facilities gave their activity reports at all times so there was a problem of missing data in some health areas which could lead to bias of information as well as an inadequate representation of the various health areas especially when comparing the two semesters of 2015 and 2016. These missing data none the less was found to be somehow homogenous for all the above health problems in children so very less impact at the level of correlation since the same health facilities provided both dependent and predictor variables used in the calculation of their correlation. Despite the fact that the results of this study show the image of malnutrition and its related factors in the Health District of Abong Mbang and can be applicable in other similar Health Districts in the East region of Cameroon, it cannot be generalized to the total population of Cameroon. Also the cross sectional aspect of the study did not permit the verification of any etiological relationship between malnutrition and diarrhoea.

\section{Conclusion and Recommendations:-}

To conclude, it can be said that the reported incidences of diarrhoea, malaria and anemia were all higher significantly in 2016 than the previous year. Also they were more preponderant in the health areas around the town of Abong Mbang. Both findings above were similar to the trends noted for malnutrition in the same Health District with a moderate correlation noted specifically between malnutrition and diarrhoea. Despite so, the results from the above data gave no reason to conclude that there was a correlation between malnutrition and diarrhoea but it should be a start point for further research in the context with more appropriate research methods so as to figure out the possible associations malnutrition might have with any of the above health problems. This will provide grounds for an effective management of the health problems already becoming of alarming extent in the Health District of Abong Mbang. Furthermore, already knowing the overall devastating nature of the bi-directional relationship between diarrhoea and malnutrition, in addition to intervening to eradicate malnutrition attention should be given to the amelioration of access to potable water as well as the general sanitation of the population.

\section{References:-}

1. Yang W, Li X, Li Y, Zhang S, Liu L, Wang X, et al. Anemia, malnutrition and their correlations with sociodemographic characteristics and feeding practices among infants aged 0-18 months in rural areas of Shaanxi province in northwestern China: a cross-sectional study. BMC Public Health. 2012(http://www.biomedcentral.com/1471-2458/12/1127).

2. Matara F, Mukona D, Zvinavashe M. Factors contributing to malnutrition among HIV positive children aged between 6 and 60 months. Journal of Nursing and Health Science. 2015;Volume 4, Issue 1(ISSN: 2320-1940).

3. Rice AL, Sacco L, Hyder A, Black RE. Malnutrition as an underlying cause of childhood deaths associated with infectious diseases in developing countries. Bulletin of the World Health Organization. 2000;78(12071221): 15 .

4. Shikur B, Deressa W, Lindtjørn B. Association between malaria and malnutrition among children aged underfive years in Adami Tulu District, south-central Ethiopia: a case-control study. BMC Public Health. 2016(DOI 10.1186/s12889-016-2838-y).

5. Simbauranga RH, Kamugisha E, Hokororo A, Kidenya BR, Makani J. Prevalence and factors associated with severe anaemia amongst under-five children hospitalized at Bugando Medical Centre, Mwanza, Tanzania. BMC Hematology. 2015(DOI 10.1186/s12878-015-0033-5).

6. Nel ED. Diarrhoea and malnutrition S Afr J Clin Nutr. 2010;23(1)(Supplement:S15-S18).

7. Gupta A. Study of the Prevalence of Diarrhoea in Children under the age of five years: It's association with Wasting. Indian JSciRes. 2014;7(1)(2250-0138):4.

8. McLean E, Coqswell M, Egli I, Wojdyla D, Benoist B. Worldwide prevalence of anemia, WHO vitamin and mineral nutrition information system, 1993-2005. Public Health Nutr 2009(12(4):444-54).

9. Sanou D, Ngnie-Teta I. Risk Factors for Anemia in Preschool Children in Sub-Saharan Africa. InTech available from http://wwwintechopencom/books/anemia/risk-factors-for-anemia-in-preschool-children-in-sub-saharanafrica. 2012(ISBN: 978-953-51-0138-3).

10. Jamison DT, Breman JG, Measham AR, Alleyne G, Claeson M, Evans DB, et al. Disease Control Priorities in Developing Countries. Oxford University Press. 2006;2nd edition(ISBN-10: 0-8213-6179-1). 
11. Friedman J, Kwena AM, Mirel LB, Kariuki SK, Terlouw DJ, Philips-Howard PA, et al. Malaria and Nutritional Status among Pre-school Children: Results from Cross-Sectional Surveys in Western Kenya. Am J Trop Med Hyg. 2005;73(4):pp. 698-704.

12. Cumber NS, Ndenkeh NJJ, Vukugah AT, Noupoue J, Tsoka-Gwegweni MJ. Malnutrition in the Health District of Abong Mbang, Cameroon. Int J Community Med Public Health (In Press). 2016.

13. Ako AA, Shimada J, Eyong GET, Fantong WF. Access to potable water and sanitation in Cameroon within the context of Millennium Development Goals (MDGS). Water Science \& Technology. 2010(doi: 10.2166/wst.2010.836).

14. Arinaitwe E, Gasasira A, Verret W, Homsy J, Wanzira H, Kakuru A, et al. The association between malnutrition and the incidence of malaria among young HIV-infected and -uninfected Ugandan children: a prospective study. Malaria Journal. 2012(http://www.malariajournal.com/content/11/1/90). 